\title{
Recovery of Liver Sinusoidal Endothelial Cells Following Monocrotaline-induced Liver Injury
}

\author{
FUMISATO OTAKA ${ }^{1,2,3}$, YOSHIYA ITO ${ }^{1,2}$, TAKUYA GOTO ${ }^{1,2,4}$, KEN KOJO $^{4}$, MINA TANABE ${ }^{1,2,3}$, \\ KANAKO HOSONO $^{1,2}$, MASATAKA MAJIMA ${ }^{1,2,5}$, WASABURO KOIZUMI ${ }^{3}$ and HIDEKI AMANO ${ }^{1,2}$ \\ ${ }^{1}$ Department of Molecular Pharmacology, Graduate School of Medical Sciences, \\ Kitasato University, Sagamihara, Japan; \\ Departments of ${ }^{2}$ Pharmacology, ${ }^{3}$ Gastroenterology, and \\ ${ }^{4}$ Surgery, Kitasato University School of Medicine, Sagamihara, Japan; \\ ${ }^{5}$ Department of Medical Therapeutics, Kanagawa Institute of Technology, Atsugi, Japan
}

\begin{abstract}
Background/Aim: Although the pathology of sinusoidal obstruction syndrome (SOS) is characterized by damage to liver sinusoidal endothelial cells (LSECS), the processes underlying LSEC repair are incompletely understood. The angiopoietin (Ang)/Tie system contributes to angiogenesis. The present study aimed to examine the processes of LSEC repair and the involvement of the Ang/Tie pathway in LSEC recovery. Materials and Methods: Experimentally, SOS was induced by intraperitoneal injection of monocrotaline (MCT) to C57/BL6 mice. Results: Levels of LSEC markers were up-regulated during the repair phase of $M C T$-induced hepatotoxicity. The damaged LSECs recovered from the injury by expanding LSECs expressing lymphatic vessel endothelial hyaluronan receptor-1 (LYVE-1) in the peri-central area of MCT-injured livers, while LSECs in the same area of uninjured livers lacked LYVE-1 expression. Bone marrow (BM)-derived cells did not incorporate into the restored LSECs. Tie2 expression was related to LSEC recovery in MCT-injured liver tissue. Conclusion: The resident LSECs neighboring uninjured tissue replace damaged LSECs in MCT-injured livers. Tie2 is involved in LSEC recovery from MCT-induced hepatotoxicity.
\end{abstract}

Sinusoidal obstruction syndrome (SOS) is a life-threatening liver injury that is caused by radiotherapy and chemotherapy for hematopoietic stem cell transplantation and liver

This article is freely accessible online.

Correspondence to: Yoshiya Ito, MD, Ph.D., Department of Pharmacology, Kitasato University School of Medicine, 1-15-1 Kitasato, Minami-ku, Sagamihara, Kanagawa 252-0374, Japan. Tel: +81 427789113, Fax: +81 427788441, e-mail: yito@kitasto-u.ac.jp

Key Words: Liver, repair, monocrotaline, LSEC, angiopoietin, Tie2. metastasis of colorectal cancer (1-4). Although the etiology of SOS remains to be clarified, SOS is thought to be initially induced by the destruction of the hepatic microvasculature (5). Administration of monocrotaline (MCT), a pyrrolizidine alkaloid, induces a type of liver injury in rodents that mimics the pathology of SOS in humans. The main underlying pathophysiology of SOS is damage to liver sinusoidal endothelial cells (LSECs), which leads to massive sinusoidal hemorrhage and centrilobular hepatocellular necrosis $(6,7)$.

Hepatic tissue repair plays a critical role in determining the final outcome of chemical-induced hepatotoxicity (8). After the liver is damaged by MCT administration, LSECs need to regenerate. The proliferation of structural cells and reconstruction of sinusoids to restore blood supply are critical events during the repair phase of MCT-induced hepatotoxicity. The formation of blood vessels is thought to result from the expansion of endothelial cells comprising neighboring vessels (9). Furthermore, recent studies have suggested that certain endothelial cell (EC) populations, including bone marrow (BM)-derived EC progenitor cells (10) participate in the recovery of LSECs after MCT-induced LSEC injury. Although restoration of LSECs is indispensable for proper liver tissue repair following MCT-induced liver injury, the processes underlying the recovery of the injured LSECs from MCT hepatotoxicity are not well defined.

The angiopoietin (Ang)/Tie system is a key regulator of angiogenesis. Ang-1 is a constitutive activator of the endothelial vascular receptor tyrosine kinase Tie2. Binding of Ang-1 to Tie2 promotes phosphorylation of Tie2 to initiate downstream effects including cell survival, migration, and permeability through the phosphatidylinositol-3 kinase/Akt signaling pathway (11). Ang-1/Tie2 axis is involved in stabilizing newly formed blood vessels via its effects on ECEC junctions and on the actin cytoskeleton (11). On the other hand, endothelial-derived Ang-2 is a context-dependent 
agonist/antagonist of Tie2 (12). Ang-2 regulates EC functions including permeability, vascular remodeling, and angiogenesis (13). In the liver, Ang-2 is expressed at low levels in resting LSECs but at high levels in regenerating LSECs (14). Ang-2 derived from LSECs promotes LSEC proliferation during the angiogenic phase of liver regeneration after partial hepatectomy in mice (14). Additionally, Ang-2/Tie2 promotes pathological angiogenesis during the development of steatohepatitis (15). Tie2 is also related to sinusoidal reconstruction following hepatic ischemia/reperfusion in mice (16). We, therefore, hypothesized that the expression of Ang-2/Tie 2 is associated with LSEC repair after acute liver injury.

Herein, we investigated the alterations in LSECs during MCT-induced liver injury. BM-derived cells did not incorporate into the recovering hepatic microvasculature during the repair phase of MCT-induced liver injury. Rather, LSECs expressing lymphatic vessel endothelial hyaluronan receptor-1 (LYVE-1) were expanded and distributed throughout the peri-central area of MCT-injured livers, while LSECs in the same area of uninjured livers lacked LYVE-1 expression. These results indicate that, during the tissue repair process following MCT injury, the injured LSECs were replaced by resident LSECs in the region of the liver adjacent to the damaged tissue. In addition, Tie 2 expression by the hepatic microvasculature was related to LSEC recovery in MCT-injured liver tissue.

\section{Materials and Methods}

Animals. Male C57BL/6 mice (8-10 weeks old) were purchased from CLEA Japan (Tokyo, Japan). Mice ubiquitously expressing green fluorescent protein (GFP) were kindly provided by Dr. Okabe (Genome Information Research Center, Osaka University, Osaka, Japan) and housed at the Kitasato University under specific pathogen-free conditions. Mice were maintained in a facility with constant humidity $(50 \% \pm 5 \%)$ and temperature $\left(25^{\circ} \mathrm{C} \pm 1^{\circ} \mathrm{C}\right)$ on a 12 $\mathrm{h}$ light/dark cycle, and were provided food and water ad libitum. All experimental procedures were approved by the Animal Experimentation and Ethics Committee of the Kitasato University School of Medicine (2019-036, 2020-103) and were performed in accordance with institutional guidelines for animal experimentation, which are based on the Guidelines for Proper Conduct of Animal Experiments published by the Science Council of Japan.

Animal procedures. Animals were fasted overnight and then injected intraperitoneally (i.p.) with $600 \mathrm{mg} / \mathrm{kg}$ MCT (Focus Biomolecules, Plymouth Meeting, PA, USA) dissolved in warm pyrogen-free saline (final concentration, $2.0 \mathrm{mg} / \mathrm{ml}$ ) to induce liver injury (7). Mice were anesthetized with pentobarbital sodium $(60 \mathrm{mg} / \mathrm{kg}, i . p$. $)$ at $0,24,48,72,96$, and $120 \mathrm{~h}$ after MCT administration, and blood was drawn. Levels of alanine transaminase (ALT) were measured using a Dri-Chem 7000 Chemistry Analyzer System (Fujifilm, Tokyo, Japan). Immediately after blood collection, livers were excised and rinsed with saline. A small section of each liver was fixed in $10 \%$ formaldehyde.
In separate experiments, MCT-treated mice received a daily subcutaneous injection of a Tie2 inhibitor (BAY-826, $50 \mathrm{mg} / \mathrm{kg}$; Millipore Sigma, Burlington, MA, USA) in $200 \mu \mathrm{l}$ of phosphatebuffered saline (PBS) (17) or vehicle (10\% ethanol). At $72 \mathrm{~h}$, mice were euthanized with pentobarbital sodium, and blood and liver samples were collected.

$B M$ transplantation. BM transplantation was performed as previously described (18). Briefly, recipient mice were treated with clodronate-loaded liposomes $(200 \mu \mathrm{l} /$ mouse; FormuMax Scientific, Inc., Palo Alto, CA, USA) to deplete tissue macrophages $48 \mathrm{~h}$ before irradiation. Donor BM cells were harvested from $\mathrm{GFP}^{+} \mathrm{WT}$ mice ( 8 weeks old). Mice were irradiated (9.8 Gy) using an MBR1505R X-ray irradiator (Hitachi Medical Co., Tokyo, Japan) fitted with a filter (copper, $0.5 \mathrm{~mm}$; aluminum, $2 \mathrm{~mm}$ ); the cumulative radiation dose was monitored throughout. Donor BM-derived mononuclear cells $\left(1 \times 10^{7}\right.$ cells $/ 200 \mu$ l PBS $)$ were injected into the tail veins of irradiated mice.

Histology. Excised liver tissues were fixed immediately with $10 \%$ formaldehyde prepared in $0.1 \mathrm{M}$ sodium phosphate buffer ( $\mathrm{pH} 7.4)$. Sections (4 $\mu \mathrm{m}$ thick) were prepared from paraffin-embedded tissues and stained with hematoxylin and eosin (H\&E). Images of H\&E-stained sections were captured under a microscope (Biozero BZ-9000 Series; KEYENCE, Osaka, Japan).

Immunofluorescence analysis. Fixed liver samples were embedded in Tissue-Tek O.C.T. compound (Sakura Finetek USA, Torrance, CA, USA), frozen at $-80^{\circ} \mathrm{C}$, and cut into $8 \mu \mathrm{m}$ sections using a cryostat. The sections were incubated overnight at $4^{\circ} \mathrm{C}$ with a rabbit anti-1 LYVE-1 polyclonal antibody (Abcam, Cambridge, UK), a goat antiLYVE-1 polyclonal antibody (R\&D Systems, Minneapolis, MN, USA), a rat anti-mouse CD31 monoclonal antibody (BD Biosciences, San Diego, CA, USA), a rat anti-mouse CD68 monoclonal antibody (Bio-Rad Laboratories, Hercules, CA, USA), and/or a goat antimouse Tie2 polyclonal antibody (R\&D Systems). After washing three times in PBS, the sections were incubated for $1 \mathrm{~h}$ at room temperature with the following secondary antibodies: Alexa Fluor 488-conjugated donkey anti-rat IgG, Alexa Fluor 594-conjugated donkey anti-rabbit IgG, Alexa Fluor 488-conjugated donkey anti-goat IgG, and/or Alexa Fluor 647-conjugated donkey anti-rabbit IgG (all from Molecular Probes, Eugene, OR, USA). Images of stained sections were captured at $\times 400$ magnification using a fluorescence microscope (Biozero BZ9000; Keyence). The area of LYVE-1-positive or CD31-positive vessel-like structures in the centrilobular regions was measured in five fields $(400 \times)$ per animal using ImageJ software, version $1.50 \mathrm{i}$ (National Institutes of Health, Bethesda, MD, USA).

Quantitative real-time $R T-P C R$. Total RNA was extracted from mouse tissues and homogenized in TRIzol reagent (Thermo Fisher Scientific, Waltham, MA, USA). Single-stranded cDNA was generated from $1 \mu \mathrm{g}$ of total RNA by reverse transcription using the ReverTra Ace qPCR RT kit (Toyobo, Osaka, Japan), according to the manufacturer's instructions. Quantitative PCR was performed using TB Green Premix Ex Taq II (Tli RNaseH Plus; Takara Bio, Shiga, Japan). The gene-specific primers used for real-time RT-PCR were designed using Primer 3 software (http://primer3.sourceforge.net/) based on data from GenBank. The primer sequences are listed in Table I. Data were normalized to the expression of glyceraldehyde3-phosphate dehydrogenase (GAPDH) in each sample. 
Table I. The primers used for reverse transcription and quantitative PCR reactions.

\begin{tabular}{lcc}
\hline Gene & Forward primer sequence (5'-3') & Reverse primer sequence (5'-3') \\
\hline MMP9 & CCCATGTCACTTTCCCTTCAC & GCCGTCCTTATCGTAGTCAGC \\
MMP13 & GTCTTCTGGCACACGCTTTTC & TCATGGGCAGCAACAATAAAC \\
CD31 & ACTTCTGAACTCCAACAGCGA & CCATGTTCTGGGGGTCTTTAT \\
LYVE-1 & GCTCTCCTCTTCTTTGGTGCT & TGACGTCATCAGCCTTCTCTT \\
VEGFR2 & GGCTGAAAAGATTGGATCAGG & CCAGGAACAATGACACCAAGA \\
VEGFR3 & CTCTCCAACTTCTTGCGTGTC & GCTTCCAGGTCTCCTCCTATC \\
Ang-1 & TGGAGGGAAAACACAAAGAAG & TGAATGTCTGACGAGAAACCA \\
Ang-2 & TACACACTGACCTTCCCCAAG & AGTCCACACTGCCATCTTCTC \\
Tie2 & CCTCCTCAACCAGAAAACATC & AGAAATCGAATAGCCATCCAC \\
Gapdh & ACATCAAGAAGGTGGTGAAGC & AAGGTGGAAGAGTGGGAGTTG
\end{tabular}

PCR, Polymerase chain reaction; MMP, matrix metalloproteinase; LYVE, lymphatic vessel endothelial hyaluronan receptor; VEGFR, vascular endothelial growth factor receptor; Ang, angiopoietin; Gapdh, glyceraldehyde-3-phosphate dehydrogenase.

Statistical analysis. All results are represented as the mean \pm standard deviation (SD). All statistical analyses were performed using GraphPad Prism software, version 8 (GraphPad Software, La Jolla, CA, USA). Data were compared between two groups using unpaired two-tailed Student's $t$-tests and between multiple groups using oneway analysis of variance followed by Tukey's post-hoc tests. A $p$ value $<0.05$ was considered statistically significant.

\section{Results}

Liver repair following MCT-induced liver injury. We sought to determine whether liver injury induced by a single injection of MCT is followed by liver tissue repair. As shown in Figure 1A, ALT levels peaked at $48 \mathrm{~h}$ post-MCT treatment, then returned to normal by $120 \mathrm{~h}$ post-treatment. To further confirm the processes of liver repair, H\&E-stained liver sections were evaluated histologically (Figure 1B). At $24 \mathrm{~h}$ post-MCT treatment, minimal alterations were noted in the liver, but substantial coagulative necrosis was observed in the centrilobular regions of the liver at $48 \mathrm{~h}$ post-MCT treatment. At 72 h, demarcated necrotic lesions infiltrated by inflammatory cells were observed. In addition, several hepatic sinusoids adjacent to the injured regions were dilated. At $96 \mathrm{~h}$, the necrotic area had decreased, and the sinusoids in the centrilobular regions had widened. At 120 $\mathrm{h}$, the hepatic architecture appeared to return to normal, and the localized area of hepatic necrosis was less obvious. These results suggest that MCT-induced liver injury peaks at $48 \mathrm{~h}$, followed by liver repair from $72 \mathrm{~h}$ and resolution by $120 \mathrm{~h}$ post-MCT treatment.

Changes in the expression of genes related to LSEC injury following MCT treatment. Next, we evaluated the expression of markers of EC injury $(7,19)$ (Figure 1C). The mRNA expression of matrix metalloproteinase (MMP) 9 and MMP13 peaked at $48 \mathrm{~h}$ post-MCT treatment, then decreased. We also examined the expression of LSEC markers, including CD31,
LYVE-1, vascular endothelial growth factor receptor (VEGFR)2, and VEGFR3 $(19,20)$. The expression of CD31 was increased in MCT-treated mice at $48 \mathrm{~h}, 72 \mathrm{~h}$, and $96 \mathrm{~h}$ post-MCT treatment. Expression of LYVE-1 was increased at $72 \mathrm{~h}$ and $96 \mathrm{~h}$, during the repair phase of MCT-induced liver injury. The expression of VEGFR2 was decreased at 48 $\mathrm{h}$ compared to pre-treatment $(0 \mathrm{~h})$ values, but this did not reach statistical significance. However, the expression of VEGFR2 was increased at $96 \mathrm{~h}$ and $120 \mathrm{~h}$ post-treatment. Furthermore, VEGFR3 was increased from $72 \mathrm{~h}$ to $120 \mathrm{~h}$ post-MCT treatment. These results suggest that LSECs were injured at $48 \mathrm{~h}$ post-MCT treatment, and LSECs recovery occurred from $72 \mathrm{~h}$ to $120 \mathrm{~h}$ post-treatment.

LSEC injury and repair during MCT-induced liver injury. We further assessed LSEC injury and repair during MCTinduced hepatotoxicity using dual immunofluorescence (Figure 2A). In untreated livers ( $0 \mathrm{~h}$ post-MCT treatment), immunoreactivity for the LSECs markers LYVE-1 and CD31 was clearly visualized in the hepatic sinusoids. However, LSECs in the centrilobular regions lacked LYVE-1 immunostaining $(7,20)$, while CD31 immunostaining was observed along hepatic sinusoids and the central vein $(\mathrm{CV})$. At $24 \mathrm{~h}$ post-MCT treatment, CD31 expression along the hepatic sinusoids had decreased. At 48 h, LYVE-1 expression was decreased in the injured regions of the liver. CD31 expression was fragmented and interspersed, suggesting destruction of the LSECs. At $72 \mathrm{~h}, \mathrm{LYVE}-1^{+}$ LSECs were distributed in the injured centrilobular regions, but the hepatic sinusoids comprising LSECs expressing LYVE-1 were dilated and discontinuous. The same was true for CD31 staining, which co-localized with LYVE-1. Additionally, inflammatory-like cells expressing CD31 accumulated in the injured regions around the CV. At $96 \mathrm{~h}$, LSECs expressing LYVE-1/CD31 extended to the injured regions around the $\mathrm{CV}$. At $120 \mathrm{~h}$, the hepatic sinusoids 

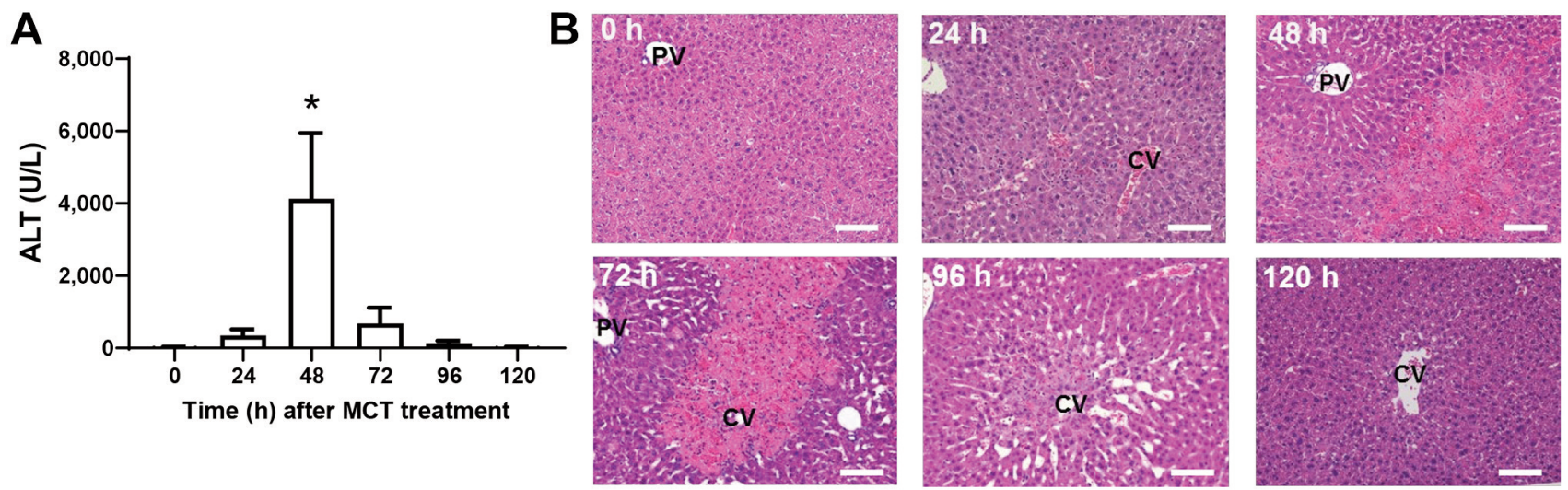

C
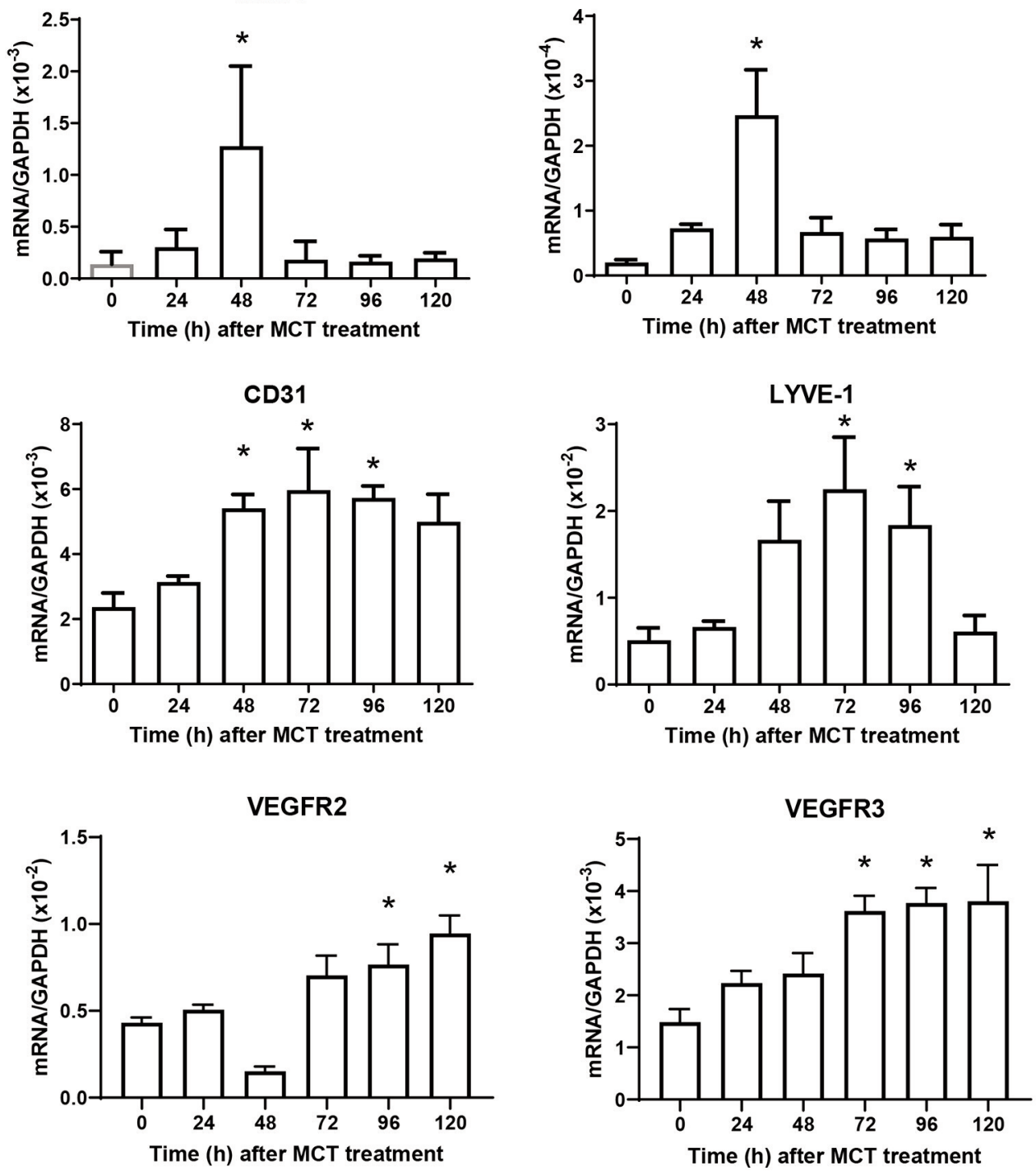

Figure 1. Liver injury after monocrotaline (MCT) treatment. (A) Time-dependent changes in ALT levels during MCT hepatotoxicity. Data are expressed as the mean $\pm S D(n=6-7$ mice per group). $* p<0.05 \mathrm{vs}$. Untreated mice (time $=0 \mathrm{~h})$. (B) Typical histological appearance of H\&E-stained liver sections at 0, 24, 48, 72, 96, and 120 h post-MCT treatment. Scale bars, $100 \mu \mathrm{m}$. CV, Central vein. PV, Portal vein. (C) Expression of MMP9, MMP13, CD31, LYVE-1,VEGFR2, and VEGFR3 in the livers of mice treated with MCT. Data are expressed as the mean $\pm S D$ ( $n=4-6$ mice per group). ${ }^{*} p<0.05$ vs. Untreated mice (time $=0 \mathrm{~h}$ ). 
A

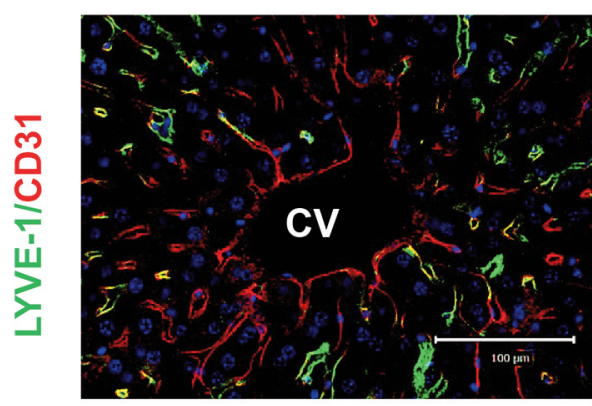

$72 \mathrm{~h}$

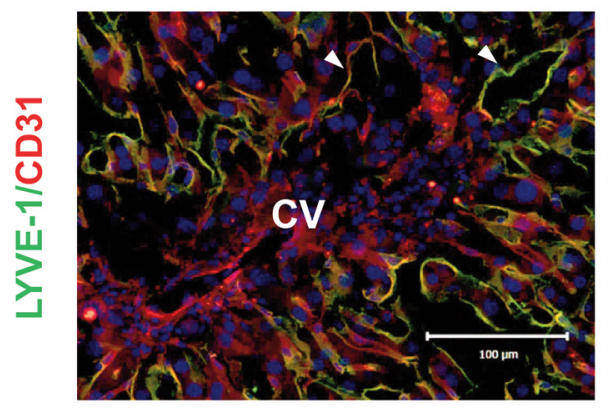

B

LYVE-1

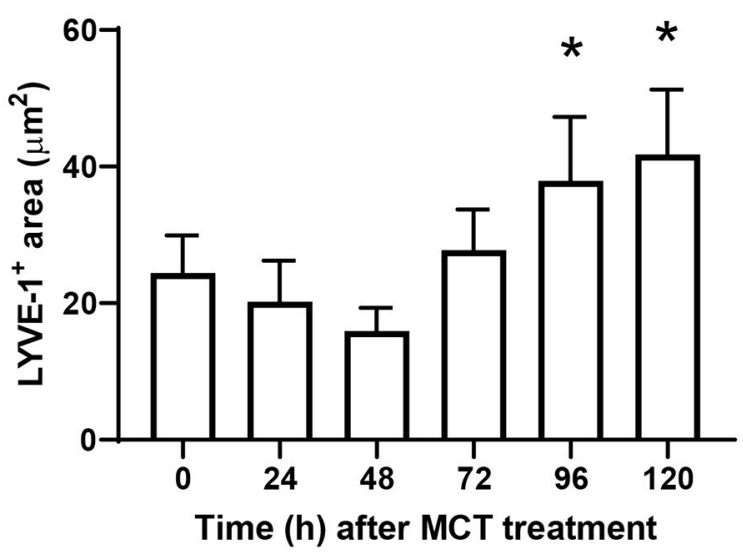

$24 \mathrm{~h}$

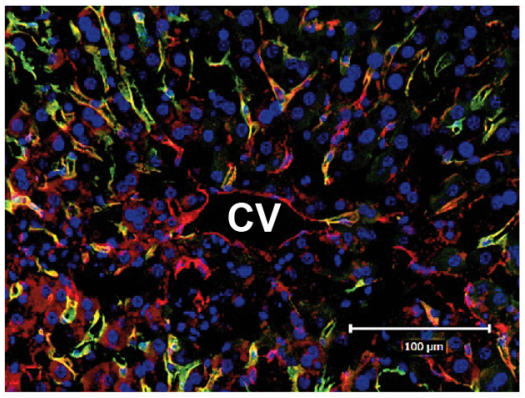

$96 \mathrm{~h}$

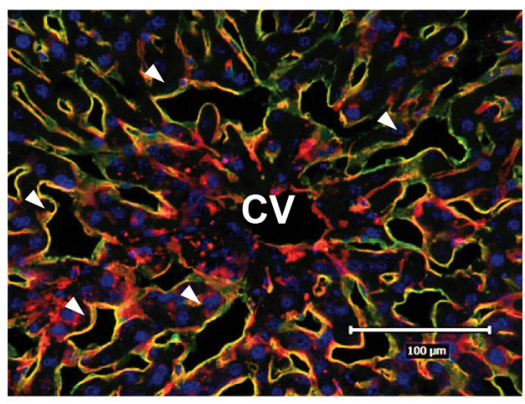

$48 \mathrm{~h}$

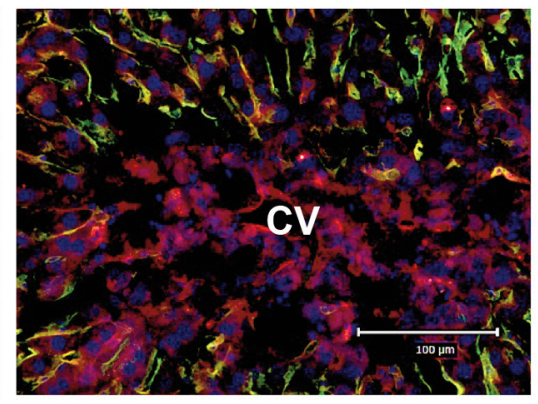

$120 \mathrm{~h}$

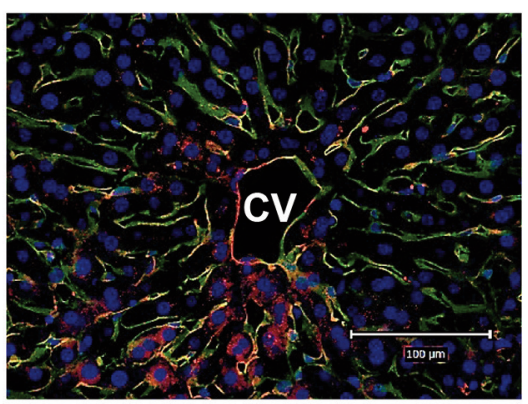

C
CD31

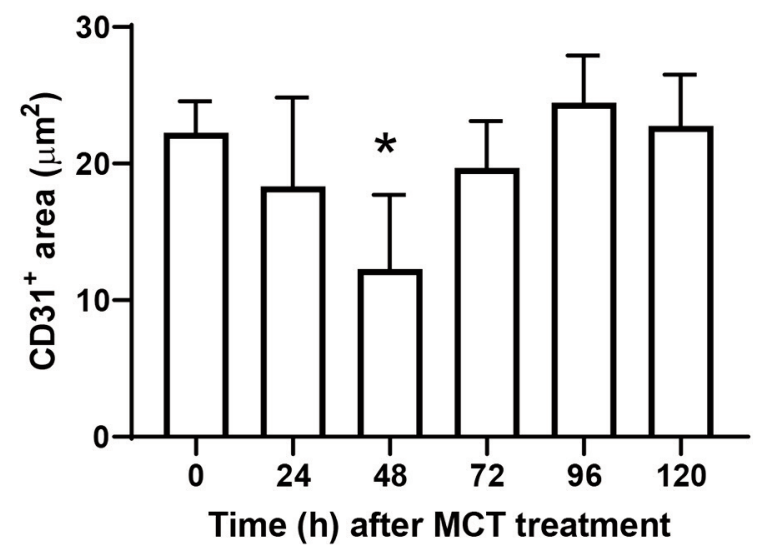

Figure 2. LSEC injury and repair during monocrotaline (MCT)-induced hepatotoxicity. (A) Immunofluorescence analysis of the LSEC marker LYVE1 (green) and CD31 (red) in the livers of mice at 0, 24, 48, 72, 96, and 120 h post-MCT treatment. Nuclei were stained with DAPI (blue). Arrowheads indicate dilated sinusoids at the peri-central area. CV, Central vein. Scale bars, $100 \mu m .(B, C)$ The area of LYVE-1 $1^{+}(B)$ and CD31+ $(C)$ vessellike structures in the centrilobular regions during MCT-induced hepatotoxicity. Data are expressed as the mean $\pm S D(n=4-6$ mice per group). * $<0.05$ vs. Untreated mice (time $=0$ h).

displayed no dilation, ran in parallel, and connected to the CV. LSECs in the centrilobular regions expressed CD31 as well as LYVE-1. We also determined the area of LYVE- $1^{+}$ or $\mathrm{CD} 31^{+}$vessel-like structures in the centrilobular regions. The area of LYVE-1 ${ }^{+}$vessels at $96 \mathrm{~h}$ and $120 \mathrm{~h}$ post-MCT treatment was increased as compared with that at $0 \mathrm{~h}$ (Figure
2B) . In addition, the area of $\mathrm{CD} 1^{+}$vessels was reduced at $48 \mathrm{~h}$ in comparison with that at $0 \mathrm{~h}$, and then returned to the pre-treatment values (Figure 2C).

LSECs did not originate from the BM. We examined the origin of the LSECs repopulating the injured tissue. Because 
BM-derived circulating EC progenitors have been reported to contribute to vascular remodeling, we performed bone marrow transplantation using donor mice with $\mathrm{GFP}^{+} \mathrm{BM}$ cells. At $72 \mathrm{~h}$ and $96 \mathrm{~h}$ post-MCT treatment, $\mathrm{GFP}^{+}$cells were distributed in the centrilobular regions (Figure 3A). However, LSECs in the sinusoidal lining expressing LYVE1 or CD31 were not $\mathrm{GFP}^{+}$, indicating that the LSECs expressing LYVE-1 or CD31 around the CV were not derived from the BM (Figure $3 \mathrm{~A}$ and $\mathrm{B}$ ). Although a few $\mathrm{CD} 31^{+}$cells in the injured regions were positive for GFP (Figure $3 \mathrm{~B}$ ), $\mathrm{GFP}^{+} / \mathrm{CD} 31^{+}$cells appeared to be inflammatory cells rather than LSECs, as these $\mathrm{GFP}^{+} / \mathrm{CD} 31^{+}$cells were also positive for CD68 (Figure 3C), indicating that recruited BM-derived cells were macrophages, not ECs. Immunofluorescence analyses suggested that the LSECs repopulating the damaged liver after MCT-induced acute liver injury were not derived from the BM, but likely derived from neighboring cells at the injury sites.

Tie2 expression during the repair phase of MCT-induced liver injury. Because the Ang-2/Tie2 pathway is reported to be involved in LSEC regeneration (14), we measured the mRNA levels of Ang-1, Ang-2, and Tie-2 (Figure 4A). The expression of Ang-1 was transiently increased at $48 \mathrm{~h}$ postMCT treatment, while the expression of Ang-2 was significantly increased at $48 \mathrm{~h}$ and $72 \mathrm{~h}$. In addition, the expression of Tie 2 was increased from $72 \mathrm{~h}$ through $120 \mathrm{~h}$ post-MCT treatment. These results indicate that the upregulation of Tie2 expression is associated with LSEC recovery after acute liver injury. We also investigated the localization of Tie 2 expression in the liver at $96 \mathrm{~h}$ post-MCT treatment (Figure 4B). Tie-2 expression co-localized with LYVE- $1^{+}$LSECs in the centrilobular regions, and several dilated hepatic sinusoids with LYVE- $1^{+}$LSECs were positive for Tie-2. In addition, a smaller population of Tie$2^{+}$cells that had accumulated in the centrilobular regions did not express LYVE-1. Of interest, dual immunofluorescence for Tie-2 and CD31 revealed that Tie-2 expression colocalized with the expression of CD31. Tie 2 expression also co-localized with the expression of CD68 in the centrilobular regions. These results indicate that Tie-2 was mainly expressed by LSECs and partly by macrophages.

Tie2 inhibition aggravated MCT-induced liver injury. To examine the role of Tie2 in LSEC recovery, mice were treated with the Tie2 inhibitor BAY-826 (Figure 5). At $72 \mathrm{~h}$ post-MCT treatment, the levels of ALT in BAY-826-treated mice were higher than in vehicle-treated mice (Figure 5A). Immunofluorescence analyses revealed that LSECs expressing CD31/LYVE-1 in the centrilobular regions were severely depleted in BAY-826-treated mice as compared with vehicle-treated mice (Figure 5B). The LYVE- ${ }^{+}$vessels and $\mathrm{CD} 31^{+}$vessels in the centrilobular regions were lower in
BAY-829-treated mice than in vehicle-treated mice (Figure 5B). MMP9 expression, but not MMP13 expression, was higher in BAY-829-treated mice than in vehicle-treated mice (Figure 5C). The mRNA levels of LYVE-1, VEGFR2, and VEGFR3 were lower in BAY-829-treated mice than in vehicle-treated mice. Furthermore, there were no statistical differences in the mRNA levels of Ang-1 and Tie2 between the two groups, although mRNA levels of Ang- 2 were lower in BAY-829-treated mice.

\section{Discussion}

In the present study, we examined the process of LSEC repair after MCT treatment in mice. LSEC repair was indicated by recovery of the architecture of the hepatic sinusoids after MCTinduced destruction. The repair process was characterized by increased expression of LSEC markers during the repair phase of MCT-induced hepatotoxicity. In intact livers, LSECs in the centrilobular regions lacked the expression of LYVE-1, while LSECs in the livers of MCT-treated mice expressed LYVE-1 during the repair phase. Further, LSECs repopulating the repaired livers were not derived from the BM, but probably from expansion of resident LSECs in tissue spared from the injury. This repair process was also associated with activation of Tie2 in LSECs.

In the MCT-induced SOS model, LSEC damage is recognized as a critical event in tissue injury $(1,2,7)$. Treatment of mice with MCT induced LSEC damage, as evidence by a reduction of LYVE- $1^{+} / \mathrm{CD} 31^{+}$expression in LSECs in the peri-central area (7) and by up-regulation of MMP9 and MMP13 $(7,19)$. Although LSEC depletion is a feature of MCT-induced acute liver injury, the processes underlying LSEC recovery are unclear. The present study demonstrated that LSECs repopulated the injured tissue, as indicated by the appearance of LYVE- $1^{+} / \mathrm{CD} 31^{+} \mathrm{LSECs}$ in the centrilobular regions. This was associated with increased expression of genes encoding CD31 and LYVE-1, as well as VEGFR2 and VEGFR3. With respect to LYVE-1 expression, as shown in Figure 2, LSECs display heterogeneous morphological features and molecular properties depending on their localization within the hepatic lobule. In intact livers, LSECs express high levels of LYVE-1 in hepatic lobules, except for in the centrilobular regions $(7,21)$. Of interest, LYVE1 expression was observed on LSECs in the centrilobular regions during the repair phase of MCT-induced liver injury. These changes suggest that LSECs are regenerating from preexisting LSECs located at the border of the injury.

In the current study, we observed sinusoidal dilation in the centrilobular regions of the liver during the repair phase. Administration of MCT destroys the architecture of the hepatic sinusoids by ablating LSECs as well as hepatic stellate cells $(6,22)$. The formation of gaps between LSECs allows erythrocytes to enter into the space of Disse, which widens 
A

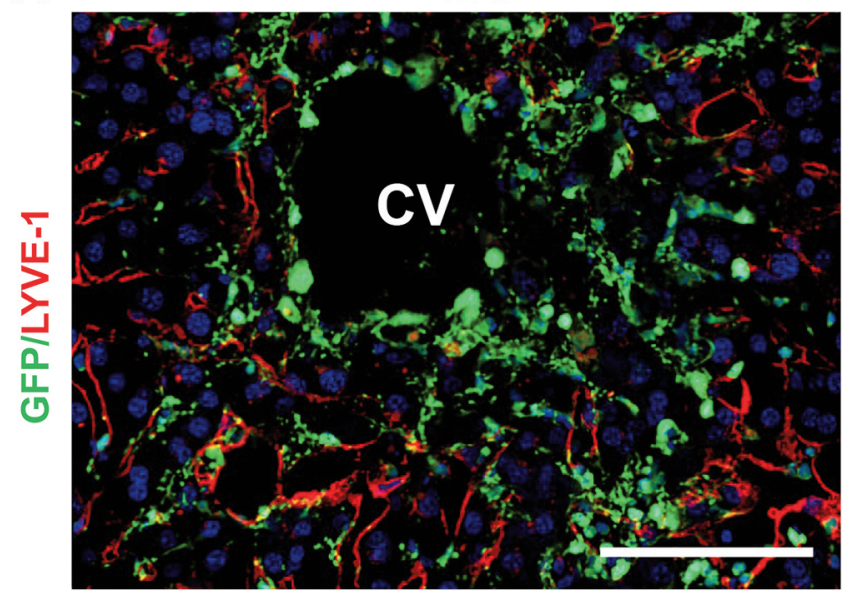

B

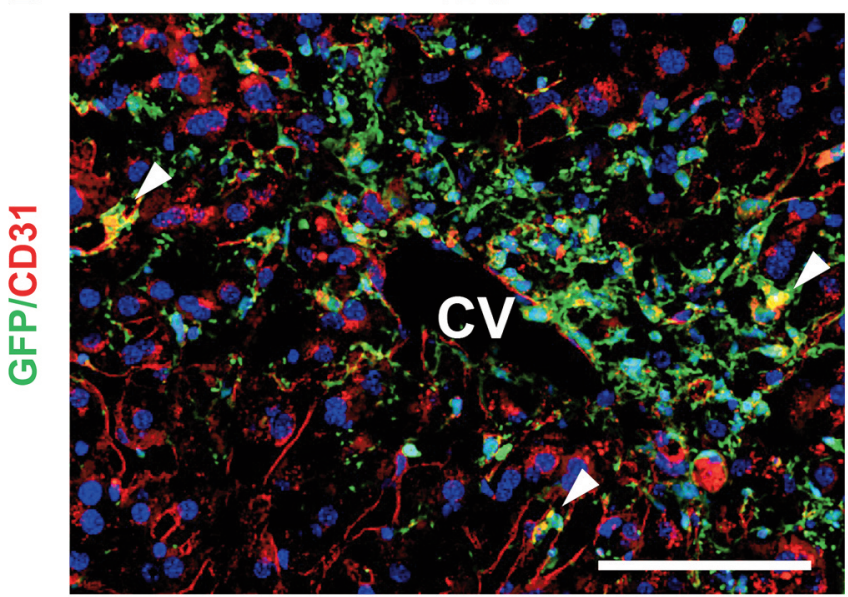

C

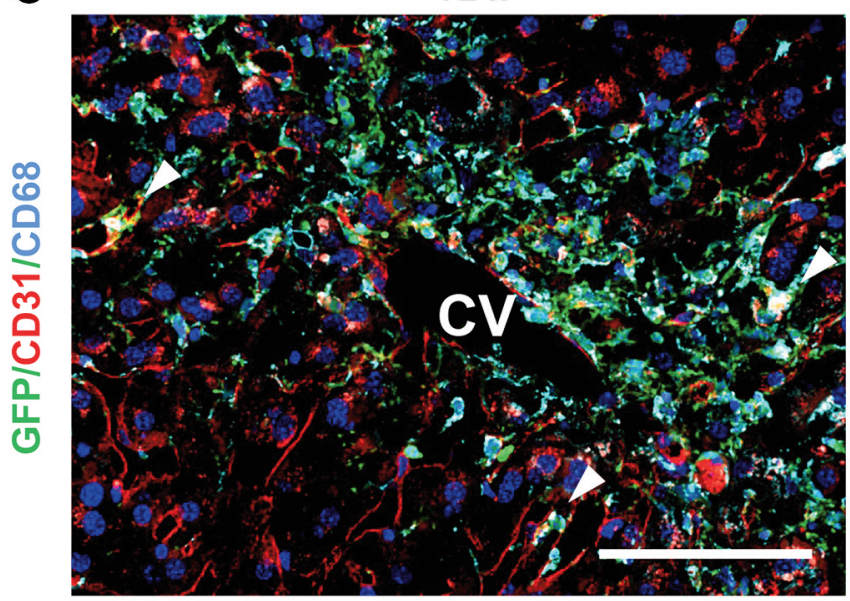

$96 \mathrm{~h}$

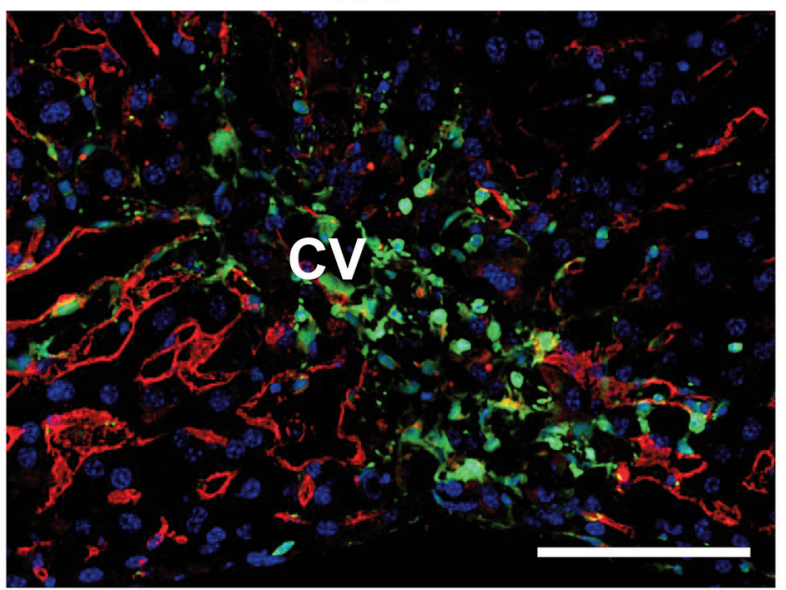

$96 \mathrm{~h}$

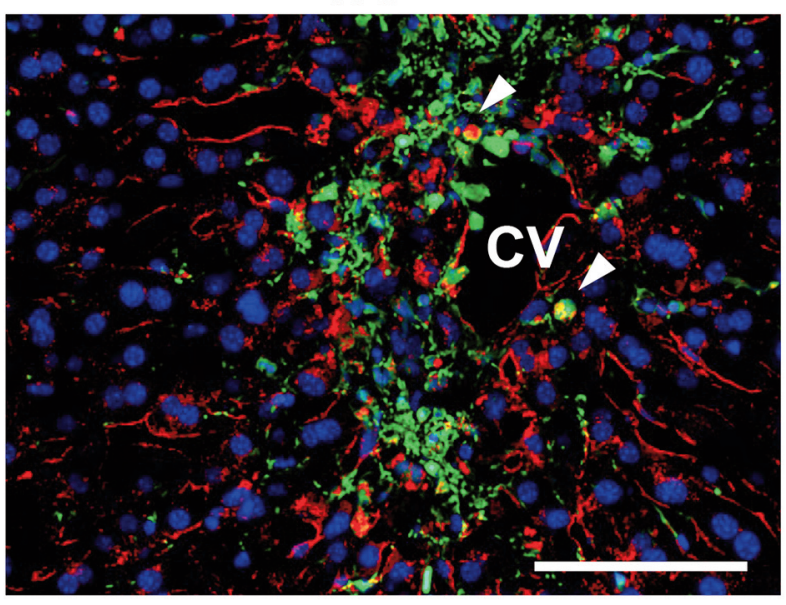

$96 \mathrm{~h}$

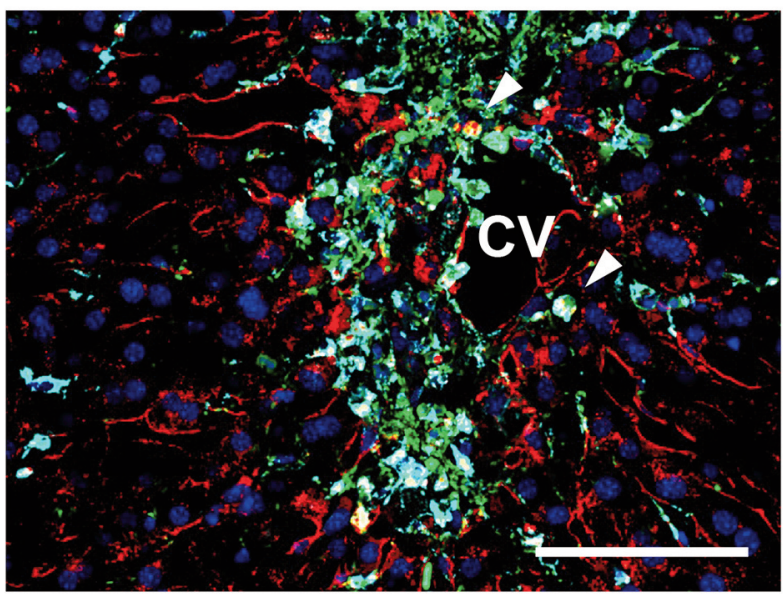

Figure 3. Accumulation of bone marrow-derived inflammatory cells in the injured liver during the repair phase of monocrotaline (MCT)-induced hepatotoxicity. (A) Representative double immunofluorescence images of GFP (green) and LYVE-1 (red) in the livers of mice at 72 h and 96 h postMCT treatment. CV, Central vein. Scale bars, $100 \mu \mathrm{m}$. (B) Representative double immunofluorescence images of GFP (green) and CD31 (red) in the livers of mice at $72 \mathrm{~h}$ and $96 \mathrm{~h}$ post-MCT treatment. Arrowheads indicate merged cells. CV, Central vein. Scale bars, $100 \mu \mathrm{m}$. (C) Representative triple immunofluorescence images of GFP (green), CD31 (red), and CD68 (cyan) in the livers of mice at $72 \mathrm{~h}$ and $96 \mathrm{~h}$ post-MCT treatment. Arrowheads indicate merged cells. CV, Central vein. Scale bars, $100 \mu \mathrm{m}$. 

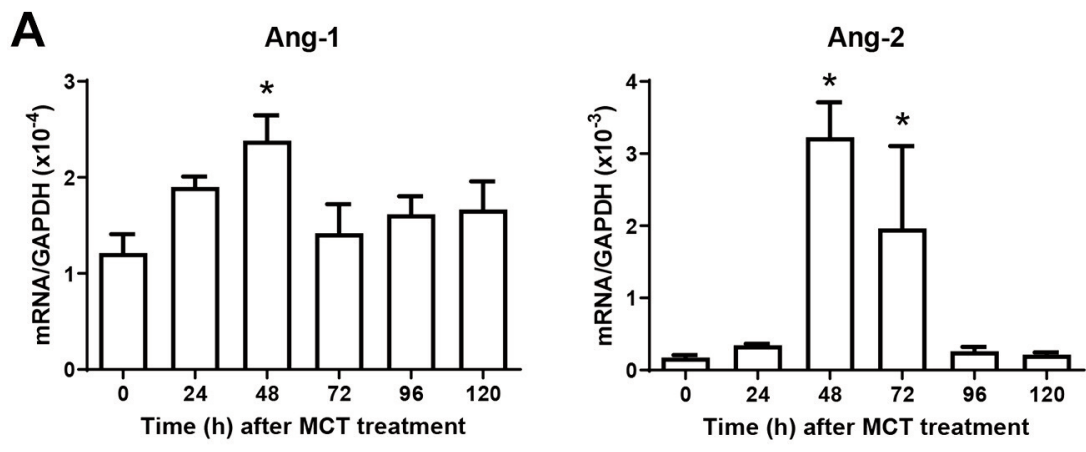

B

Tie2/LYVE-1

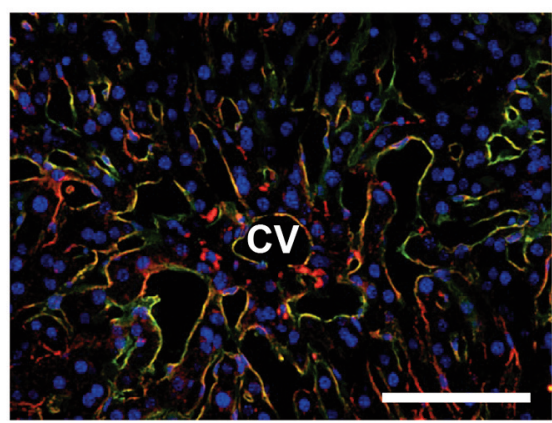

Tie2/CD31

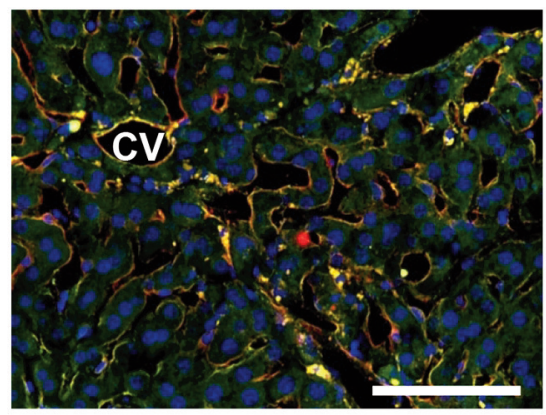

Tie2

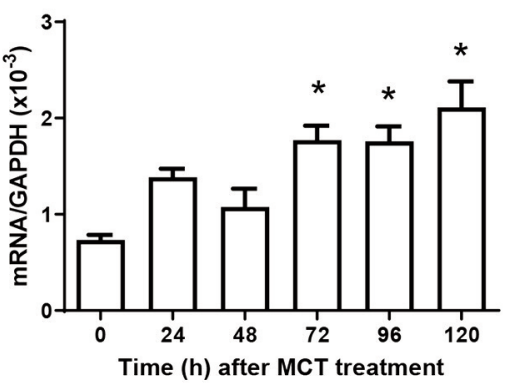

Tie2/CD68

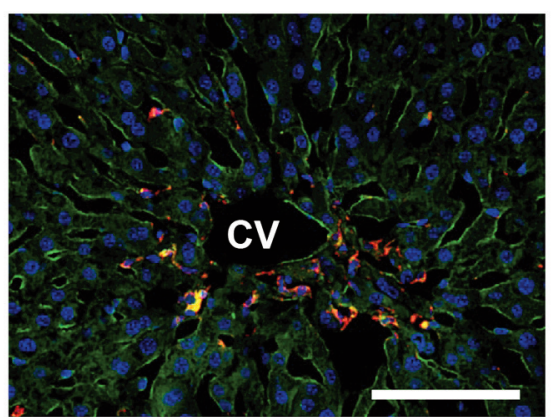

Figure 4. Expression of Ang/Tie2 in the liver during MCT-induced hepatotoxicity. (A) Expression of Ang-1, Ang-2, and Tie 2 in the livers of mice treated with MCT. Data are expressed as the mean $\pm S D\left(n=4-6\right.$ mice per group). ${ }^{*} p<0.05 v$ s. Untreated mice (time $\left.=0 h\right)$. (B) Representative immunofluorescence images of Tie2 (red) and LYVE-1 (green), Tie2 (green) and CD31 (red), or Tie2 (green) and CD68 (red) in the livers of mice at $96 \mathrm{~h}$ post-MCT treatment. CV, Central vein. Scale bars, $100 \mu \mathrm{m}$.

hepatic sinusoids. Thus, the loss of the sinusoidal lining around injured hepatic sinusoids contributes to sinusoidal dilation. Sinusoidal dilation with congestion has been reported in human SOS induced by oxaliplatin-based chemotherapy used prior to the resection of colorectal liver metastases (23$25)$. The grade of sinusoidal dilation is associated with the extent of peri-sinusoidal fibrosis. However, in the MCTinduced mouse SOS model, liver fibrosis around the CV was not observed. Taken together, these data indicate that sinusoidal dilation is a feature of repair from MCT-induced acute liver injury in mice; however, the underlying mechanisms of sinusoidal dilation remain to be clarified.

MCT-damaged LSECs are replaced in the recovering liver by newly formed LSECs. In a rat MCT model, BM-derived $\mathrm{CD} 133^{+} / \mathrm{CD} 45^{+}$progenitor cells replace the injured LSECs (10). Consistent with this, irradiation results in the recruitment and incorporation of BM-derived mononuclear cells to repair the injured vasculature (26). By contrast, the present immunofluorescence analyses revealed that BMderived cells were not incorporated into the regenerating liver vasculature, indicating that BM-derived cells are not recruited to the sites of the injured LSECs and do not differentiate into mature LSECs. Rather, BM-derived cells expressing CD31 expressed the macrophage marker CD68. These discrepant results may be due to differences in the experimental protocols used, including the animal strain, the MCT dose, and the endothelial surface markers analyzed. However, the possibility that BM-derived cells expressing CD68 might contribute to LSEC repair after damage cannot be excluded. In addition, a recent report suggests that LSEC repopulation after MCT-induced liver injury and subsequent radiation does not require BM-derived endothelial progenitor cells, but is induced by small subsets of endogenous CD157/CD200 double-positive endothelial cells residing in the vascular walls of the portal veins (27). CD157/CD200 double-positive endothelial cells originating from the portal vein migrated into the hepatic sinusoids to replace the damaged LSECs. Although endothelial vascular stem cells are primarily involved in LSEC recovery in response to MCT and radiation, it requires about 3 weeks for repair and recovery of the damaged LSECs to occur. Further studies are needed to examine whether the local vascular endothelial stem cells resided in the portal veins contribute to LSEC recovery in this model. 


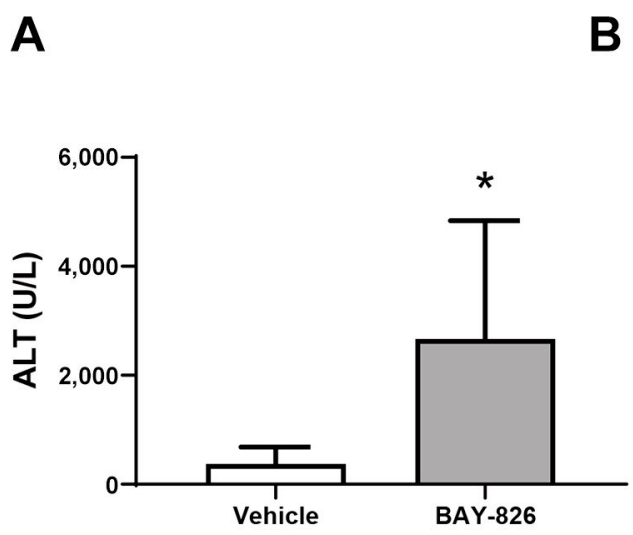

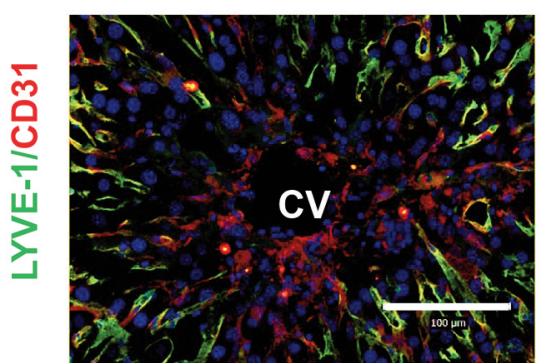

Vehicle

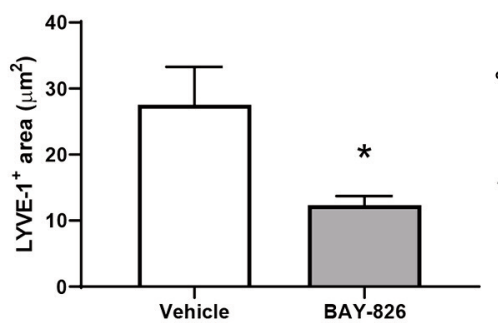

MMP13

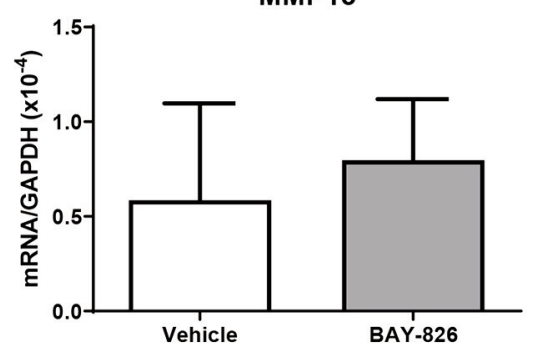

VEGFR2

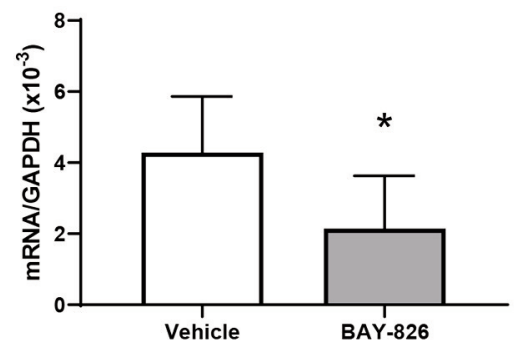

Ang-2

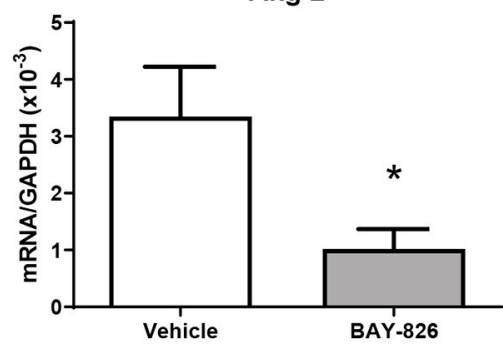

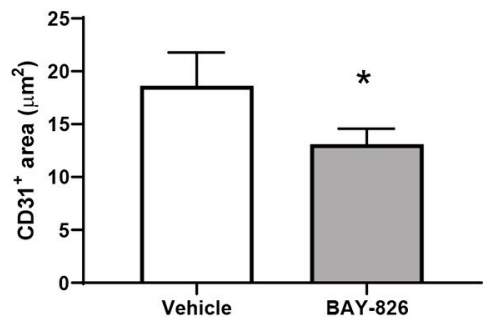

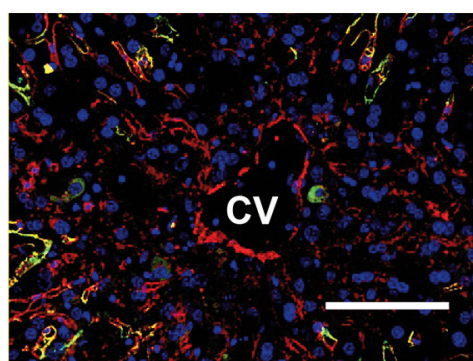

BAY-826

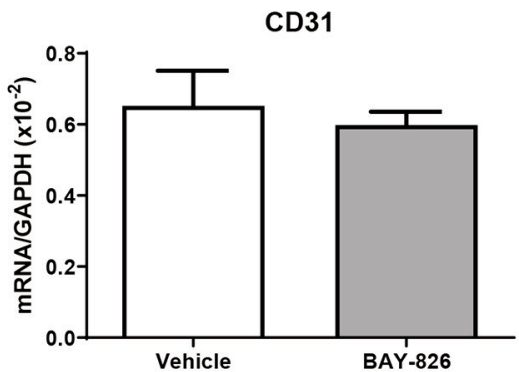

VEGFR3

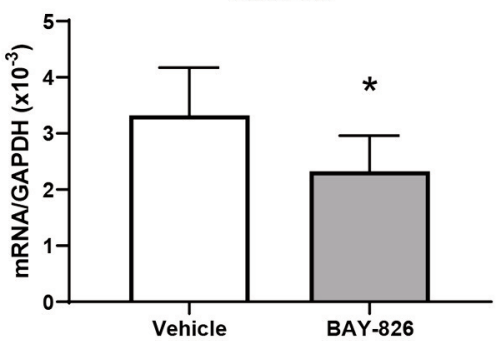

Tie2

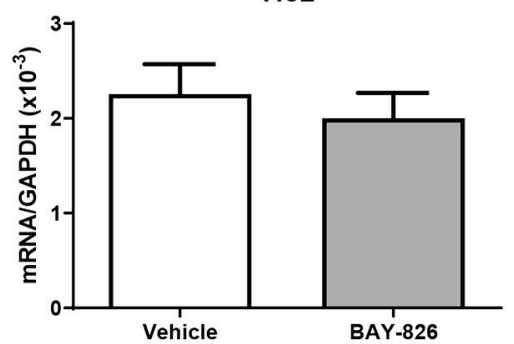

Figure 5. Effect of the Tie2 inhibitor BAY-826 on monocrotaline (MCT)-induced LSEC injury. (A) ALT levels in mice treated with BAY-826 and vehicle at $72 \mathrm{~h}$ post-MCT treatment. Data are expressed as the mean $\pm S D$ ( $n=5$ mice per group). ${ }^{*} p<0.05$ vs. vehicle. (B) Immunofluorescence photos of LYVE-1 (green) and CD31 (red) in the livers of mice treated with BAY-826 or vehicle at $72 \mathrm{~h}$ post-MCT treatment. The area of LYVE-1+ and $C D 31^{+}$vessel-like structures in the centrilobular regions at $72 \mathrm{~h}$ post-MCT treatment. Data are expressed as the mean $\pm S D(n=3-5 \mathrm{mice}$ per group). ${ }^{*} p<0.05$ vs. vehicle. (C) Expression of MMP9, MMP13, CD31, LYVE-1, VEGFR2, VEGFR3, Ang-1, Ang-2, and Tie2 in the livers of mice treated with BAY-826 or vehicle at $72 \mathrm{~h}$ post-MCT treatment. Data are expressed as the mean $\pm S D(n=5-6$ mice per group). *p<0.05 vs. vehicle. 
Ang-1 is a constitutive activator of the endothelial Tie2 receptor and is involved in stabilizing newly formed vasculature. In the present study, Ang-1 was transiently upregulated at $48 \mathrm{~h}$ post-MCT treatment but was not upregulated during the repair phase. These results suggest that Ang-1 plays a minor role in LSEC repair from MCT damage. The angiogenic biomarker Ang-2 was up-regulated after MCT-induced liver injury and was associated with upregulation of Tie2 in the repair phase of MCT hepatotoxicity. Tie 2 are mainly expressed by ECs (14). Consistent with this, Tie2 was expressed by LSECs in the injured liver. Inhibition of Tie 2 with BAY-826 aggravated liver injury at $72 \mathrm{~h}$ postMCT treatment, which was associated with reduction in LYVE- $1^{+}$- and CD $31^{+}$-vessels. This response was associated with LSEC injury, as indicated by reduced mRNA levels of LYVE-1, VEGFR2, and VEGFR3. These results suggest that Tie2 activation in LSECs promotes LSEC recovery after MCT-induced hepatotoxicity. Further studies are needed to validate the critical role of the Ang-2/Tie2 axis in the recovery of LSECs from MCT-induced damage.

The present study has several limitations. First, we used an animal model to investigate the liver repair process. Second, we established a mouse model of SOS by administration of MCT. In humans, the main causes of SOS are chemotherapy and radiotherapy $(1,2,28)$. Third, MCTinduced liver injury progressed acutely within 24-48 h of MCT administration, and the injury resolved quickly, with near-complete recovery by $120 \mathrm{~h}$ after MCT treatment. Accordingly, liver function is efficiently restored in this model. By contrast, human SOS is caused by chronic exposure to chemotherapy for colorectal liver metastasis or myeloablative chemoirradiation for hematopoietic cell transplantation. Liver injuries persist for a long time in human SOS patients, as sinusoidal dilatation only regresses 9 months after the cessation of chemotherapy (29).

\section{Conclusion}

We evaluated the process of MCT-induced LSEC injury and repair. The present study suggests that pre-existing LSECs in close proximity to the site of injury replace damaged LSECs in the inner sinusoidal lining. Tie2 signaling appears to be involved in LSEC recovery after MCT-induced liver injury. However, the mechanisms through which Tie2 enhances the proliferative capacity of LSECs during the repair phase of MCT-induced hepatotoxicity remain to be clarified. Insights into the restoration of LSECs after MCT administration have important implications for understanding injury-induced inflammation and tissue repair during SOS.

\section{Conflicts of Interest}

The Authors declare that there are no conflicts of interest.

\section{Authors' Contributions}

FO designed the research, carried out the experiments, performed data collection, data analysis and wrote the manuscript. YI reviewed pathological data, analyzed the data, and wrote the manuscript. TG, $\mathrm{KK}, \mathrm{MT}$, and KH carried out the experiments, reviewed pathological data and analyzed the data. MM, WK, and HA designed the research, supervised progress, and reviewed the manuscript.

\section{Acknowledgements}

The Authors thank Michiko Ogino and Kyoko Yoshikawa for technical assistance. This work was supported by Grants from the Japanese Ministry of Education, Culture, Sports, Science, and Technology (MEXT) (grant nos. 19K09156 to YI and 20K17702 to $\mathrm{KK})$.

\section{References}

1 DeLeve LD, Shulman HM and McDonald GB: Toxic injury to hepatic sinusoids: sinusoidal obstruction syndrome (venoocclusive disease). Semin Liver Dis 22(1): 27-42, 2002. PMID: 11928077. DOI: $10.1055 / \mathrm{s}-2002-23204$

2 Fan CQ and Crawford JM: Sinusoidal obstruction syndrome (hepatic veno-occlusive disease). J Clin Exp Hepatol 4(4): 332346, 2014. PMID: 25755580. DOI: 10.1016/j.jceh.2014.10.002

3 Mohty M, Malard F, Abecassis M, Aerts E, Alaskar AS, Aljurf M, Arat M, Bader P, Baron F, Bazarbachi A, Blaise D, Ciceri F, Corbacioglu S, Dalle JH, Duarte RF, Fukuda T, Huynh A, Masszi T, Michallet M, Nagler A, NiChonghaile M, Pagluica T, Peters C, Petersen FB, Richardson PG, Ruutu T, Savani BN, Wallhult E, Yakoub-Agha I and Carreras E: Sinusoidal obstruction syndrome/veno-occlusive disease: current situation and perspectivesa position statement from the European Society for Blood and Marrow Transplantation (EBMT). Bone Marrow Transplant 50(6): 781-789, 2015. PMID: 25798682. DOI: 10.1038/bmt.2015.52

4 Nassereddine S, Alsubait S and Tabbara I: Sinusoidal obstruction syndrome (Veno-occlusive Disease) following hematopoietic stem cell transplant: Insights and therapeutic advances. Anticancer Res 38(5): 2597-2605, 2018. PMID: 29715079. DOI: 10.21873/anticanres.12501

5 Bonifazi F, Barbato F, Ravaioli F, Sessa M, Defrancesco I, Arpinati M, Cavo M and Colecchia A: Diagnosis and treatment of VOD/SOS after allogeneic hematopoietic stem cell transplantation. Front Immunol 11: 489, 2020. PMID: 32318059. DOI: $10.3389 /$ fimmu.2020.00489

6 DeLeve LD, McCuskey RS, Wang X, Hu L, McCuskey MK, Epstein RB and Kanel GC: Characterization of a reproducible rat model of hepatic veno-occlusive disease. Hepatology 29(6): 17791791, 1999. PMID: 10347121. DOI: 10.1002/hep.510290615

7 Otaka F, Ito Y, Inoue T, Ohkubo H, Nishizawa N, Kojo K, Betto $T$, Yamane S, Narumiya S, Koizumi $W$ and Majima $M$ : Thromboxane $\mathrm{A}_{2}$ receptor signaling in endothelial cells attenuates monocrotaline-induced liver injury. Toxicol Appl Pharmacol 381: 114733, 2019. PMID: 31470032. DOI: 10.1016/ j.taap.2019.114733

8 Mehendale HM: Tissue repair: an important determinant of final outcome of toxicant-induced injury. Toxicol Pathol 33(1): 41-51, 2005. PMID: 15805055. DOI: 10.1080/01926230590881808 
9 Chung AS and Ferrara N: Developmental and pathological angiogenesis. Annu Rev Cell Dev Biol 27: 563-584, 2011. PMID: 21756109. DOI: 10.1146/annurev-cellbio-092910-154002

10 Harb R, Xie G, Lutzko C, Guo Y, Wang X, Hill CK, Kanel GC and DeLeve LD: Bone marrow progenitor cells repair rat hepatic sinusoidal endothelial cells after liver injury. Gastroenterology 137(2): 704-712, 2009. PMID: 19447108. DOI: 10.1053/ j.gastro.2009.05.009

11 Saharinen P, Eklund L and Alitalo K: Therapeutic targeting of the angiopoietin-TIE pathway. Nat Rev Drug Discov 16(9): 635661, 2017. PMID: 28529319. DOI: 10.1038/nrd.2016.278

12 Kim M, Allen B, Korhonen EA, Nitschké M, Yang HW, Baluk P, Saharinen P, Alitalo K, Daly C, Thurston G and McDonald DM: Opposing actions of angiopoietin-2 on Tie2 signaling and FOXO1 activation. J Clin Invest 126(9): 3511-3525, 2016. PMID: 27548529. DOI: 10.1172/JCI84871

13 Ju R, Zhuang ZW, Zhang J, Lanahan AA, Kyriakides T, Sessa WC and Simons M: Angiopoietin-2 secretion by endothelial cell exosomes: regulation by the phosphatidylinositol 3-kinase (PI3K)/Akt/endothelial nitric oxide synthase (eNOS) and syndecan-4/syntenin pathways. J Biol Chem 289(1): 510-519, 2014. PMID: 24235146. DOI: 10.1074/jbc.M113.506899

$14 \mathrm{Hu} \mathrm{J}$, Srivastava K, Wieland M, Runge A, Mogler C, Besemfelder E, Terhardt D, Vogel MJ, Cao L, Korn C, Bartels S, Thomas $\mathrm{M}$ and Augustin HG: Endothelial cell-derived angiopoietin-2 controls liver regeneration as a spatiotemporal rheostat. Science 343(6169): 416-419, 2014. PMID: 24458641. DOI: $10.1126 /$ science. 1244880

15 Lefere S, Van de Velde F, Hoorens A, Raevens S, Van Campenhout S, Vandierendonck A, Neyt S, Vandeghinste B, Vanhove C, Debbaut C, Verhelst X, Van Dorpe J, Van Steenkiste C, Casteleyn C, Lapauw B, Van Vlierberghe H, Geerts A and Devisscher L: Angiopoietin-2 promotes pathological angiogenesis and is a therapeutic target in murine nonalcoholic fatty liver disease. Hepatology 69(3): 1087-1104, 2019. PMID: 30259536. DOI: 10.1002/hep.30294

16 Ohkubo H, Ito Y, Minamino T, Eshima K, Kojo K, Okizaki S, Hirata M, Shibuya M, Watanabe M and Majima M: VEGFR1positive macrophages facilitate liver repair and sinusoidal reconstruction after hepatic ischemia/reperfusion injury. PLoS One 9(8): e105533, 2014. PMID: 25162491. DOI: 10.1371/ journal.pone. 0105533

17 Schneider H, Szabo E, Machado RA, Broggini-Tenzer A, Walter A, Lobell M, Heldmann D, Süssmeier F, Grünewald S and Weller M: Novel TIE-2 inhibitor BAY-826 displays in vivo efficacy in experimental syngeneic murine glioma models. J Neurochem 140(1): 170-182, 2017. PMID: 27787897. DOI: 10.1111/jnc.13877

18 Nishizawa N, Ito Y, Eshima K, Ohkubo H, Kojo K, Inoue T, Raouf J, Jakobsson PJ, Uematsu S, Akira S, Narumiya S, Watanabe $M$ and Majima $M$ : Inhibition of microsomal prostaglandin E synthase-1 facilitates liver repair after hepatic injury in mice. J Hepatol 69(1): 110-120, 2018. PMID: 29458169. DOI: $10.1016 / \mathrm{j} . j h e p .2018 .02 .009$

19 Otaka F, Ito Y, Goto T, Eshima K, Amano H, Koizumi W and Majima M: Platelets prevent the development of monocrotalineinduced liver injury in mice. Toxicol Lett 335: 71-81, 2020. PMID: 33122006. DOI: 10.1016/j.toxlet.2020.10.007

20 Ding BS, Nolan DJ, Butler JM, James D, Babazadeh AO, Rosenwaks Z, Mittal V, Kobayashi H, Shido K, Lyden D, Sato $\mathrm{TN}$, Rabbany SY and Rafii S: Inductive angiocrine signals from sinusoidal endothelium are required for liver regeneration. Nature 468(7321): 310-315, 2010. PMID: 21068842. DOI: 10.1038 /nature09493

21 Mouta Carreira C, Nasser SM, di Tomaso E, Padera TP, Boucher Y, Tomarev SI and Jain RK: LYVE-1 is not restricted to the lymph vessels: expression in normal liver blood sinusoids and down-regulation in human liver cancer and cirrhosis. Cancer Res 61(22): 8079-8084, 2001. PMID: 11719431.

22 DeLeve LD, Ito Y, Bethea NW, McCuskey MK, Wang X and McCuskey RS: Embolization by sinusoidal lining cells obstructs the microcirculation in rat sinusoidal obstruction syndrome. Am J Physiol Gastrointest Liver Physiol 284(6): G1045-G1052, 2003. PMID: 12584111. DOI: 10.1152/ajpgi.00526.2002

23 Rubbia-Brandt L, Audard V, Sartoretti P, Roth AD, Brezault C, Le Charpentier M, Dousset B, Morel P, Soubrane O, Chaussade S, Mentha G and Terris B: Severe hepatic sinusoidal obstruction associated with oxaliplatin-based chemotherapy in patients with metastatic colorectal cancer. Ann Oncol 15(3): 460-466, 2004. PMID: 14998849. DOI: 10.1093/annonc/mdh095

24 Agostini J, Benoist S, Seman M, Julié C, Imbeaud S, Letourneur F, Cagnard N, Rougier P, Brouquet A, Zucman-Rossi J and Laurent-Puig P: Identification of molecular pathways involved in oxaliplatin-associated sinusoidal dilatation. J Hepatol 56(4): 869876, 2012. PMID: 22200551. DOI: 10.1016/j.jhep.2011.10.023

25 Jarzabek MA, Proctor WR, Vogt J, Desai R, Dicker P, Cain G, Raja R, Brodbeck J, Stevens D, van der Stok EP, Martens JWM, Verhoef C, Hegde PS, Byrne AT and Tarrant JM: Interrogation of transcriptomic changes associated with drug-induced hepatic sinusoidal dilatation in colorectal cancer. PLoS One 13(6): e0198099, 2018. PMID: 29879147. DOI: 10.1371/journal.pone.0198099

26 Singhal M, Liu X, Inverso D, Jiang K, Dai J, He H, Bartels S, Li W, Abdul Pari AA, Gengenbacher N, Besemfelder E, Hui L, Augustin $\mathrm{HG}$ and $\mathrm{Hu} \mathrm{J}$ : Endothelial cell fitness dictates the source of regenerating liver vasculature. J Exp Med 215(10): 2497-2508, 2018. PMID: 30194265. DOI: 10.1084/jem.20180008

27 Wakabayashi T, Naito H, Suehiro JI, Lin Y, Kawaji H, Iba T, Kouno T, Ishikawa-Kato S, Furuno M, Takara K, Muramatsu F, Weizhen J, Kidoya H, Ishihara K, Hayashizaki Y, Nishida K, Yoder MC and Takakura N: CD157 marks tissue-resident endothelial stem cells with homeostatic and regenerative properties. Cell Stem Cell 22(3): 384-397.e6, 2018. PMID: 29429943. DOI: 10.1016/j.stem.2018.01.010

28 Coppell JA, Richardson PG, Soiffer R, Martin PL, Kernan NA, Chen A, Guinan E, Vogelsang G, Krishnan A, Giralt S, Revta C, Carreau NA, Iacobelli M, Carreras E, Ruutu T, Barbui T, Antin $\mathrm{JH}$ and Niederwieser D: Hepatic veno-occlusive disease following stem cell transplantation: incidence, clinical course, and outcome. Biol Blood Marrow Transplant 16(2): 157-168, 2010. PMID: 19766729. DOI: 10.1016/j.bbmt.2009.08.024

29 Vigano L, De Rosa G, Toso C, Andres A, Ferrero A, Roth A, Sperti E, Majno P and Rubbia-Brandt L: Reversibility of chemotherapy-related liver injury. J Hepatol 67(1): 84-91, 2017. PMID: 28284915. DOI: 10.1016/j.jhep.2017.02.031

Received May 29, 2021

Revised June 21, 2021

Accepted June 25, 2021 